\title{
Impaired driving and legalization of recreational cannabis
}

\author{
Sarah B. Windle MPH, Crystal Sequeira MScA, Kristian B. Filion PhD, Brett D. Thombs PhD, \\ Pauline Reynier MSc, Roland Grad MD MSc, Carolyn Ells PhD, Mark J. Eisenberg MD MPH
}

Cite as: CMAJ 2021 April 6;193:E481-5. doi: 10.1503/cmaj.191032

See related article at www.cmajopen.ca/lookup/doi/10.9778/cmajo.20200155

${ }^{66} \mathrm{D}$ on't drive high." This is the message that the government of Canada wanted all drivers to take to heart after the legalization of recreational cannabis in October 2018. However, the association between the use of legal recreational cannabis and impaired driving is not clear. Although cannabis consumption has the potential to substantially impair psychomotor skills and cognitive functions reducing performance on critical tracking and divided-attention tasks, slowing reaction time and increasing lane weaving ${ }^{1}$ - the influence of cannabis on driving tasks varies by individual, dose and methods of consumption, and time since consumption before driving. ${ }^{2}$ Some studies have found associations between cannabis use and impairment of driving - including in driving simulators, closed-course driving and epidemiologic studies ${ }^{3}-$ but others have not. ${ }^{4}$ Furthermore, the findings of studies are frequently confounded by users' consumption of cannabis with other legal (e.g., tobacco, alcohol) and illegal (e.g., opioids, methamphetamines) substances, ${ }^{3}$ making it difficult to estimate the relative contribution of cannabis consumption to motor vehicle collisions. This in turn leads to difficulty in establishing the optimal approach to educating both health care providers and the public about the effects of cannabis, so as to deter driving under the influence of cannabis.

We analyze the association between recreational cannabis legalization and fatal motor vehicle collision rates and discuss the implications of existing evidence for Canadian policy and physicians' practice.

\section{What is known about the use of cannabis and driving in Canada?}

According to survey data from Statistics Canada, the proportion of Canadians who reported having consumed cannabis in the past 3 months increased from 14\% to 17\% from 2018 (before legalization) to $2019 .{ }^{5}$ Although individuals may be more likely to report cannabis use after legalization, ${ }^{6}$ these data suggest that overall use may have increased since legalization. Among all

\section{KEY POINTS}

- Analyses of data suggest that legalization of recreational cannabis in United States jurisdictions may be associated with a small but significant increase in fatal motor vehicle collisions and fatalities, which, if extrapolated to the Canadian context, could result in as many as 308 additional driving fatalities annually.

- Efforts to deter cannabis-impaired driving in Canada include the implementation of federal tetrahydrocannabinol driving limits ( $\geq 2 \mathrm{ng} / \mathrm{mL}$ ) with associated penalties, the development of measures and tools for the detection of cannabis impairment, and public education about the risks of cannabisimpaired driving.

- Health care professionals have an opportunity to educate patients about the safer use of cannabis products, including advising against cannabis use and driving (especially in combination with alcohol), with a suggested wait time of at least 6 hours before driving.

recent users of cannabis with a driver's licence, $13 \%$ reported driving within 2 hours of cannabis consumption. ${ }^{5}$ This proportion appears to be unchanged before and after legalization, but the absolute number of individuals who reported driving after recent cannabis use increased from 573000 to 622000 owing to the larger overall number of users. ${ }^{5}$ In addition, nearly $20 \%$ of users who reported driving after consuming cannabis also reported coconsuming alcohol. ${ }^{5}$

An analysis based on 2012 survey data estimated cannabisrelated collisions in Canada to cost $\$ 1.1$ billion (95\% confidence interval [Cl] $\$ 37$ million to $\$ 2.9$ billion) annually in societal and economic costs, with drivers aged 34 years and younger responsible for the bulk of the costs. ${ }^{7}$ The authors estimated 75 cannabis-attributable deaths (95\% Cl 0-213), 4407 injuries (95\% Cl 20-11549) and 7794 collisions resulting in property damage only (95\% Cl 3107-13 086); these findings indicate lack of clarity regarding the specific effect of cannabis on motor vehicle collisions. ${ }^{7}$ 


\section{How has legalization of recreational cannabis affected the incidence of motor vehicle collisions in other jurisdictions?}

We published an analysis of data collected from 2007 to 2018 in jurisdictions in the United States that have legalized recreational cannabis ${ }^{8}$ to inform an estimate of the potential impact of legalization on motor vehicle fatalities in Canada. For our study, we retrieved the annual number of fatal motor vehicle collisions and associated deaths for 2007-2018 from the US Fatality Analysis Reporting System for the 11 jurisdictions with legalized recreational cannabis in effect before 2019 (as of January 2021, recreational cannabis use has been made legal in 15 states and the District of Columbia), and examined the association between legalization of recreational cannabis and fatal motor vehicle collisions. We compared jurisdiction-specific rates before and after legalization and then meta-analyzed estimates across jurisdictions. We found that legalization was associated with increased rates of fatal motor vehicle collisions (incidence rate ratio [IRR] 1.15, 95\% $\mathrm{Cl} 1.06-1.26)$ and associated deaths (IRR $1.16,95 \% \mathrm{Cl} 1.06-1.27$ ). ${ }^{8}$ Our findings suggested that legalizing cannabis on a national scale could result in an additional 4843 motor vehicle fatalities per year in the US, an increase of 16\%. In Canada, 1922 motor vehicle fatalities were reported in $2018 ;{ }^{\circ}$ a $16 \%$ relative increase would correspond to 308 additional deaths annually.

Previous studies have also examined the association between legalization of recreational cannabis and fatal motor vehicle collisions. A 2016 study found that the proportion of drivers in Washington state involved in a fatal crash who tested positive for tetrahydrocannabinol (THC) approximately doubled (8\% to $17 \%$ ) in the year after legalization. ${ }^{10}$ Although the mere presence of THC does not necessarily denote impairment, the results suggest at minimum that more drivers had consumed cannabis after legalization. The authors of a 2019 study compared changes in traffic fatalities in 3 states with recreational legalization (Colorado, Washington and Oregon) versus neighbouring states without legalization. ${ }^{11}$ They found a temporary increase in traffic fatalities in the first year after legalization, which the authors attributed to a possible celebratory response to legalization or an increase in inexperienced cannabis users, or both. They also hypothesized that later reductions in traffic fatalities could be a result of drivers substituting cannabis for alcohol use.

Another 2019 study also compared fatal crashes after recreational cannabis legalization in Colorado and Washington, ${ }^{12}$ showing a nonsignificant trend toward increased fatal motor vehicle crashes over the 5 years before and after legalization compared with control states. A separate analysis that compared rates before and after commercial dispensaries opened (as legalization and commercial sale began at different times) found a significant increase in fatal motor vehicle collisions $(+1.8$ fatal collisions/billion vehicle miles travelled, $95 \% \mathrm{Cl} 0.4-$ 3.7) after commercial dispensing began. A 2020 study using similar data found an increase in motor vehicle fatalities in Colorado (+1.5 fatalities/billion vehicle miles travelled, $p=0.047)$ but not in Washington $(+0.08$ fatalities/billion vehicle miles travelled, $p=0.67$ ) after the legalization of recreational cannabis retail sales. ${ }^{13}$ The authors hypothesized that differences between the states (e.g., greater retail density, cannabis use and cannabis tourism) may have contributed to the observed increase in traffic fatalities in Colorado but not Washington. Another study was conducted in 2020, which found an increase in motor vehicle fatalities (+2.1 fatalities/billion vehicle miles travelled, $95 \% \mathrm{Cl} 1.3-3.0$ ) in 4 states (Colorado, Washington, Oregon and Alaska) after legalization of recreational cannabis retail sales, compared with 20 control states without legalized recreational or medical cannabis. ${ }^{14}$

Overall, available data from ecological studies suggest that legalization of recreational cannabis may be associated with a small but important relative increase in fatal motor vehicle collisions in the US. This increase may or may not be temporary. Further robust analyses should be conducted as more data become available.

\section{Are steps to detect and deter cannabis- impaired driving in Canada likely to be effective?}

In Canada, prudent regulatory and public health measures to deter cannabis-impaired driving may be able to prevent increases in cannabis-impaired driving and its consequences since the legalization of recreational cannabis. However, a multidisciplinary response is required for optimal detection and deterrence..$^{15}$ Substantial uncertainty exists concerning the optimal use of available measures and tools for detecting cannabisimpaired driving. ${ }^{2}$

Canada presently uses psychomotor assessments that can be performed at the roadside to screen for drug impairment. ${ }^{3}$ These include Standardized Field Sobriety Tests: the one-leg stand, horizontal gaze nystagmus and walk-and-turn. ${ }^{16}$ These tests were developed for assessing impairment related to alcohol use, and their validity for detecting impairment due to cannabis is uncertain. ${ }^{3}$ After a failed Standardized Field Sobriety Test, an officer with specialized training, such as a drug recognition expert, will conduct more complex neurologic and ophthalmological tests to assess potential impairment. However, there are few such experts in Canada, as training is expensive and timeconsuming, and law enforcement's ability to make experts available across broad jurisdictions is strained. . $^{2,17}$ In addition, drug recognition experts are not medically trained, and the accuracy with which officers can detect impairment and attribute it to a particular class of drugs varies. ${ }^{18}$ The validity of both Standardized Field Sobriety Tests and the drug recognition expert program for cannabis impairment remains uncertain, and other methods to either complement or replace these approaches should be investigated.

Biochemical measures of cannabis in blood, urine or saliva may be used in addition to psychomotor assessments when considering level of impairment. Canada's Bill C-46 (2018) permits police to perform roadside testing of saliva for THC, with several testing devices currently approved and others being 
evaluated. ${ }^{19}$ Bill C-46 also specifies threshold driving "per se" limits for THC $(2-5 \mathrm{ng} / \mathrm{mL}$ and $\geq 5 \mathrm{ng} / \mathrm{mL})$ with minimum impaired driving penalties and higher penalties for lower levels of THC if alcohol is also present $(\geq 2.5 \mathrm{ng} / \mathrm{mL}$ THC with blood alcohol concentration $\geq 0.5 \mathrm{mg} / \mathrm{mL}$ ). ${ }^{19}$ Provinces and territories may implement stricter policies (Quebec and Saskatchewan have zero-tolerance policies, with penalties for any detectable THC). ${ }^{20,21}$ The practical application of these limits and their ability to withstand legal challenges remain unclear, however, because they are not based on a demonstrated correlation between THC levels and driving impairment. ${ }^{17,22}$

Tetrahydrocannabinol is fat soluble and therefore passes quickly from blood into the brain and other organs, where its metabolites can remain for extended periods of time, making the accurate biochemical measurement of impairment difficult. ${ }^{3}$ Furthermore, relative impairment at a certain concentration of THC may potentially differ between individuals owing to variation in tolerance, ${ }^{23}$ and chronic daily users of cannabis may continue to have detectable levels of THC in saliva or urine after weeks or even months of abstinence. ${ }^{24,25}$ The varied methods of cannabis consumption (e.g., smoking, vaping, edibles) also confound measurement, given different patterns of THC rise and fall in body fluids. ${ }^{2}$ Substantial improvement in the accuracy of current biochemical measures to detect cannabis impairment is needed to both ensure public safety and protect the rights of legal cannabis users.

Despite uncertainty regarding test accuracy, messaging that reinforces to the public that impaired driving will be detected and penalties enforced is likely to be effective in deterring cannabis-impaired driving. Public awareness of the establishment of alcohol limit laws introduced between 1982 and 2000 in US jurisdictions is estimated to have reduced alcohol-related collisions by $14 \%-15 \% .{ }^{26,27}$ The establishment of federal limits for driving after consuming THC may therefore prove to be useful and provide Canada with an advantage over deterrence strategies in the US. Of the 11 US jurisdictions that had legalization regulations for recreational cannabis in effect by 2020 , only 4 had cannabis-specific driving limits. ${ }^{8}$

Other deterrence strategies include "zero-tolerance" policies for young drivers, sobriety spot checks roadside, and administrative sanctions (e.g., ticketing, fines, vehicle seizure, licence suspension) applied after impaired driving convictions. ${ }^{2} \mathrm{~A}$ recent review considered that proactive policing techniques, when highly publicized and visible, can have an immediate and large effect on reducing impaired driving. ${ }^{28}$

\section{Can health care professionals help to prevent cannabis-impaired driving?}

Brief counselling interventions in primary care settings have been shown to reduce problematic alcohol use and other risky behaviours ${ }^{29}$ and may be adapted to counselling about cannabis use and driving. There is no evidence to suggest that driving risks are different for people who use cannabis for therapeutic versus recreational purposes. Therefore, the same information may be imparted to both groups.
Canada's Lower-Risk Cannabis Use Guidelines recommend several evidence-based steps that patients could use to reduce their risk of several harms (Appendix 1, available at www.cmaj. ca/lookup/doi/10.1503/cmaj.191032/tab-related-content). ${ }^{30}$ These steps include choosing lower-potency products, limiting to occasional use, and choosing nonsmoking methods of consumption such as vapourizers or edibles (however, the guideline cautions that although edibles are safer for respiratory health, it is easier to consume larger doses and experience more severe impairment as a result of delayed psychoactive effects). ${ }^{31}$ The guideline also recommends against cannabis use and driving (especially in combination with alcohol), with a suggested wait time of at least 6 hours before driving. ${ }^{30}$

Box 1 lists some evidence-based statements of fact that may be useful to health care practitioners when cautioning patients who use cannabis regarding driving high. Patients may not be aware that consumption in motor vehicles (even when parked) is prohibited, and that any cannabis in the vehicle must be stored out of reach of the driver (e.g., in the trunk). ${ }^{32}$ National guidance and provincial legislation behooves physicians to advise patients using any form of cannabis (including synthetic cannabinoids) that they may exceed legal THC limits even if they wait 6 hours

Box 1: Patient tool for cannabis-impaired driving in Canada

- Cannabis use impairs driving, making it more difficult to carry out tasks like staying in your lane, maintaining a consistent speed, making good decisions on the road and avoiding hazards. ${ }^{1,2}$

- Drinking alcohol and using cannabis together impairs driving more than either drug alone. ${ }^{5}$

- Consumption in motor vehicles (even when parked) is prohibited. Cannabis in motor vehicles must be stored in a closed area out of reach of the driver and passengers (e.g., in the trunk). ${ }^{3}$

- Drugged driving is illegal. The police have many tools available to detect impaired driving, including sobriety and saliva tests roadside, blood testing and evaluation by a drug recognition expert. Penalties for a drugged driving offence include a maximum $\$ 1000$ fine (THC $>2 \mathrm{ng} / \mathrm{mL}$ but $<5 \mathrm{ng} / \mathrm{mL}$ ), or for higher levels of THC ( $\geq 5 \mathrm{ng} / \mathrm{mL}):^{4}$

- First offence: mandatory minimum $\$ 1000$ fine; possibility of up to 10 years in prison

- Second offence: mandatory minimum 30 days in prison (maximum 10 years)

- Third offence: mandatory minimum 120 days in prison (maximum 10 years)

- Cannabis affects each person differently, and its effects depend on the product used and the method and amount of consumption. With edibles in particular, it can take longer for the subjective effects to be felt and could result in consuming more than intended. When you consume cannabis, its effects make it difficult for you to know that you are impaired. ${ }^{2}$

- Do not take chances. Plan ahead if you are going to consume, either by making alternative transportation arrangements, or consuming well in advance of when you intend to drive (at least 6 hours). ${ }^{2}$ 
after consumption before driving (particularly in provinces like Quebec and Saskatchewan, which have zero-tolerance policies for THC), ${ }^{17,33,34}$ and emphasize the possible penalties for exceeding legal limits (regardless of impairment). ${ }^{35}$ Although peak THC concentrations in plasma typically occur within 5-30 minutes of consumption and taper off after 2-4 hours, impairment may persist for 3-6 hours after consumption, depending on route and individual factors. Health care professionals should also be aware of discretionary or mandatory reporting requirements in their jurisdiction related to substance use and driving, ${ }^{36}$ although knowledge gaps remain concerning determining fitness to drive, particularly for long-term regular users of cannabis.

\section{Conclusion}

Evidence from the US suggests that there is the potential for a small but important increase in fatal motor vehicle collisions after the legalization of recreational cannabis in Canada, which could result in about 308 additional road fatalities annually, ${ }^{8}$ as well as thousands more nonfatal injuries. However, the implementation of impaired driving regulations and educational campaigns, including federal THC driving limits and public awareness of these limits, may contribute to the prevention of potential increases in cannabis-impaired driving in Canada. Health care professionals should provide patients who use cannabis with clear, evidence-based guidance for safer cannabis use.

\section{References}

1. Busardo FP, Pellegrini M, Klein J, et al. Neurocognitive correlates in driving under the influence of cannabis. CNS Neurol Disord Drug Targets 2017;16:534-40.

2. A framework for the legalization and regulation of cannabis in Canada: The final report of the Task Force on Cannabis Legalization and Regulation. Ottawa: Health Canada; 2016. Available: http://healthycanadians.gc.ca/task -force-marijuana-groupe-etude/framework-cadre/alt/framework-cadre-eng .pdf (accessed 2019 July 5).

3. Capler R, Bilsker D, Van Pelt K, et al. Cannabis use and driving: evidence review. Burnaby (BC): Canadian Drug Policy Coalition; 2017. Available: http://drugpolicy. ca/wp-content/uploads/2016/11/CDPC_Cannabis-and-Driving_Evidence-Review -Full_Jan31-2017_FINAL.pdf (accessed 2019 June 20).

4. Elvik R. Risk of road accident associated with the use of drugs: a systematic review and meta-analysis of evidence from epidemiological studies. Accid Anal Prev 2013;60:254-67.

5. National Cannabis Survey, first quarter 2019. Ottawa: Statistics Canada; 2019. Available: https://www150.statcan.gc.ca/n1/daily-quotidien/190502/dq190502a-eng. htm (accessed 2019 May 31).

6. Canadian Cannabis Survey 2018 Summary. Ottawa: Government of Canada; 2018. Available: www.canada.ca/en/services/health/publications/drugs-health -products/canadian-cannabis-survey-2018-summary.html (accessed 2019 July 4).

7. Wettlaufer A, Florica RO, Asbridge M, et al. Estimating the harms and costs of cannabis-attributable collisions in the Canadian provinces. Drug Alcohol Depend 2017;173:185-90.

8. Windle SB, Eisenberg MJ, Reynier P, et al. Association between legalization of recreational cannabis and fatal motor vehicle collisions in the United States: an ecological study. CMAJ Open 2021;9:E233-41.

9. Canadian motor vehicle traffic collision statistics: 2018. Ottawa: Government of Canada [Transport Canada]; 2019. Available: https://tc.canada.ca/en/canadian -motor-vehicle-traffic-collision-statistics-2018 (accessed 2019 July 5).

10. Tefft BC, Arnold LS, Grabowski JG. Prevalence of marijuana involvement in fatal crashes: Washington, 2010-2014. Washington (D.C): AAA Foundation for Traffic Safety; 2016. Available: https://aaafoundation.org/wp-content/uploads/2017/12/ PrevalenceOfMarijuanalnvolvement.pdf (accessed 2019 July 5).
11. Lane TJ, Hall W. Traffic fatalities within US states that have legalized recreational cannabis sales and their neighbours. Addiction 2019;114:847-56.

12. Aydelotte JD, Mardock AL, Mancheski CA, et al. Fatal crashes in the 5 years after recreational marijuana legalization in Colorado and Washington. Accid Anal Prev 2019;132:105284.

13. Santaella-Tenorio J, Wheeler-Martin K, DiMaggio CJ, et al. Association of recreational cannabis laws in Colorado and Washington State with changes in traffic fatalities, 2005-2017. JAMA Intern Med 2020;180:1061-8.

14. Kamer RS, Warshafsky S, Kamer GC. Change in traffic fatality rates in the first 4 states to legalize recreational marijuana. JAMA Intern Med 2020;180:1119-20.

15. Marillier M, Verstraete AG. Driving under the influence of drugs. WIREs Forensic Sci 2019;1:e1326.

16. Bosker WM, Theunissen EL, Conen S, et al. A placebo-controlled study to assess Standardized Field Sobriety Tests performance during alcohol and cannabis intoxication in heavy cannabis users and accuracy of point of collection testing devices for detecting THC in oral fluid. Psychopharmacology (Berl) 2012;223:439-46.

17. Peaire A, Filbert A, Smith D, et al. Report on drug per se limits. Ottawa: Canadian Society of Forensic Sciences; 2017. Available: www.csfs.ca/wp-content/ uploads/2017/09/Report-on-Drug-Per-Se-Limit.pdf (accessed 2019 June 20).

18. Beirness DJ, LeCavalier J, Singhal D. Evaluation of the Drug Evaluation and Classification program: a critical review of the evidence. Traffic Inj Prev 2007;8: 368-76.

19. Bill C-46. Ottawa: Parliament of Canada; 2018. Available: www.parl.ca/ DocumentViewer/en/42-1/bill/C-46/royal-assent (accessed 2019 Feb. 26).

20. Regulation of cannabis in Québec. Québec City: Government of Quebec; 2019. Available: https://encadrementcannabis.gouv.qc.ca/en/ (accessed 2019 June 3).

21. Cannabis in Saskatchewan. Regina: Government of Saskatchewan; 2019. Available: www.saskatchewan.ca/government/cannabis-in-saskatchewan (accessed 2019 June 3).

22. Roth $A$. The uneasy case for marijuana as chemical impairment under a sciencebased jurisprudence of dangerousness. California Law Review 2015;103:841-918.

23. Desrosiers NA, Ramaekers JG, Chauchard E, et al. Smoked cannabis' psychomotor and neurocognitive effects in occasional and frequent smokers. $J$ Anal Toxicol 2015;39:251-61.

24. Bosker WM, Karschner EL, Lee D, et al. Psychomotor function in chronic daily cannabis smokers during sustained abstinence. PLoS One 2013;8:e53127.

25. Ellis GM Jr, Mann MA, Judson BA, et al. Excretion patterns of cannabinoid metabolites after last use in a group of chronic users. Clin Pharmacol Ther 1985;38:572-8.

26. Tippetts AS, Voas RB, Fell JC, et al. A meta-analysis of. 08 BAC laws in 19 jurisdictions in the United States. Accid Anal Prev 2005;37:149-61.

27. Villaveces A, Cummings P, Koepsell TD, et al. Association of alcohol-related laws with deaths due to motor vehicle and motorcycle crashes in the United States, 1980-1997. Am J Epidemiol 2003;157:131-40.

28. Fell JC. Approaches for reducing alcohol-impaired driving: evidence-based legislation, law enforcement strategies, sanctions, and alcohol-control policies. Forensic Sci Rev 2019;31:161-84.

29. Final recommendation statement: unhealthy alcohol use in adolescents and adults: screening and behavioral counseling interventions. Rockville (MD): U.S. Preventive Services Task Force; 2018. Available: www.uspreventiveservicestaskforce. org/Page/Document/RecommendationStatementFinal/unhealthy-alcohol-use -in-adolescents-and-adults-screening-and-behavioral-counseling-interventions (accessed 2019 Oct. 23).

30. Fischer B, Russell C, Sabioni P, et al. Lower-risk cannabis use guidelines: a comprehensive update of evidence and recommendations. Am J Public Health 2017;107:e1-12.

31. Grewal JK, Loh LC. Health considerations of the legalization of cannabis edibles. CMAJ 2020;192:E1-2.

32. Lancione S, Wade K, Windle SB, et al. Non-medical cannabis in North America: an overview of regulatory approaches. Public Health 2020;178:7-14.

33. Huestis MA, Milman G, Mendu DR, et al. Evaluation of the on-site Draeger DrugTest 5000 in occasional and chronic frequent smokers following controlled cannabis smoking. Semantic Scholar; 2013. Available: www.semanticscholar. org/paper/Evaluation-of-the-on-site-Draeger-DrugTest-5000-in-Huestis-Milman /8991d00dc75bb423f92bbfe69d3bb64ef31fb4ec\#citing-papers (accessed 2019 Oct. 3). 
34. Tuv SS, Krabseth H, Karinen R, et al. Prevalence of synthetic cannabinoids in blood samples from Norwegian drivers suspected of impaired driving during a seven weeks period. Accid Anal Prev 2014;62:26-31.

35. Impaired driving laws. Ottawa: Department of Justice; 2019. Available: www. justice.gc.ca/eng/cj-jp/sidl-rlcfa/ (accessed 2019 July 4).
36. Hit the brakes: Do you need to report your patient's fitness to drive? Ottawa: Canadian Medical Protective Association; 2019. Available: www.cmpa-acpm. ca/en/advice-publications/browse-articles/2019/hit-the-brakes-do-you-need -to-report-your-patients-fitness-to-drive (accessed 2019 Nov. 20).

\section{Competing interests: None declared.}

This article has been peer reviewed.

Affiliations: Lady Davis Institute (Windle, Sequeira, Filion, Thombs, Reynier, Grad, Ells, Eisenberg), Jewish General Hospital; Department of Epidemiology, Biostatistics and Occupational Health (Windle, Filion, Thombs, Eisenberg), McGill University; Department of Medicine (Filion, Thombs, Eisenberg), McGill University; Departments of Psychiatry, of Psychology, and of Educational and Counselling Psychology (Thombs), McGill University; Department of Family Medicine (Grad, Ells), McGill University; Biomedical Ethics Unit, Division of Experimental Medicine, and Department of Social Sciences of Medicine (Ells), McGill University; Division of Cardiology (Eisenberg), Jewish General Hospital, Montréal, Que.

Contributors: Sarah Windle and Crystal Sequeira contributed equally as joint first authors. Sarah Windle, Mark Eisenberg and Kristian Filion contributed to the conception and design of the work. Sarah Windle and Crystal Sequeira jointly drafted the manuscript. All of the authors revised the manuscript for important intellectual content, gave final approval of the version to be published and agreed to be accountable for all aspects of the work.

Funding: This study was funded by the Canadian Institutes of Health Research (\#SHI-155407). Sarah Windle is supported by a Maysie MacSporran Graduate Studentship, Alma Mater Fellowship, and Graduate Excellence Award from McGill University. Kristian Filion is supported by a Senior Research Scholar award from the Fonds de recherche du Québec - Santé (FRQ-S; Quebec Foundation for Research - Health) and a William Dawson Scholar award from McGill University. Brett Thombs is supported by a FRQ-S research salary award.

Content licence: This is an Open Access article distributed in accordance with the terms of the Creative Commons Attribution (CC BY-NC-ND 4.0) licence, which permits use, distribution and reproduction in any medium, provided that the original publication is properly cited, the use is noncommercial (i.e., research or educational use), and no modifications or adaptations are made. See: https://creativecommons.org/licenses/by-nc-nd/4.0/

Correspondence to: Mark Eisenberg, mark.eisenberg@mcgill.ca 